\title{
The Routledge Handbook of Translation and Ethics
}

\section{Section III: Institutions}

\section{Ethics in the Translation Industry}

\author{
Joss Moorkens ${ }^{1} \&$ Marta Rocchi $^{2}$ \\ 1 School of Applied Language and Intercultural Studies/ADAPT Centre, Dublin City \\ University \\ ${ }^{2}$ Dublin City University Business School/Irish Institute of Digital Business, Dublin City \\ University
}

\section{A. INTRODUCTION}

This chapter considers ethical issues related to the contemporary translation industry, about which little, to our knowledge, has previously been written to date. Many publications concerning ethics in translation have theorised on whether the translator should be constrained by fidelity to the source text or should be permitted to refuse to translate material that they consider unethical (Chesterman 1997; Van Wyke 2012), or on how translators negotiate a liminal space between cultures (Pym 2012) without consideration of the ethical issues related to the translation industry and the way it relates to its main stakeholders. Exceptions include work by Tymoczko (2007) and Abdallah (2010) on asymmetries of power and Drugan's (2017) consideration of social responsibility and responsibility to clients, which harks back to a discussion of ethical dimensions of functionalism by Nord (1997) and the need to balance fidelity to the source, target, and facilitation of intercultural communication. In this chapter, we focus on ethical concerns experienced by (and directed at) different stakeholders in the translation industry at various levels in translation production. These stakeholders' responsibilities and priorities may differ depending on the organisation's size, 
geographical location, and length of experience of the actors, and this in turn will affect the level of trust in the interrelationships (Pym 2004). These factors have been heavily influenced by globalisation, a process enabled by translation and that influences the increasingly distributed production networks that carry out translation work (Cronin 2012). The work of Abdallah $(2010,2014)$ has been particularly important in establishing the tensions, loyalties, and disparate levels of agency within a translation production network.

Relationships within these production networks are highly transactional and subject to the competing imperatives of time, cost, and quality. In recent years, the agents involved at different levels in the translation industry have been constantly and increasingly adapting the way they work and communicate with each other in light of the massive introduction of technology throughout different stages of the translation process: indeed, automation does not concern solely the translation itself, but also project management processes and the platforms devoted to the interaction between translators, companies, and clients.

Given the complexity of the translation networks and the multi-level engagement of different actors, the chapter is articulated as follows: we first review the historical trajectory of the translation industry, highlighting how the perception of its social responsibilities has been evolving in recent decades, as with many other industries. The following section introduces relevant ethical issues specific to the translation industry, structuring them according to the ethical challenges experienced by its different stakeholders. Finally, the last section emphasises three emerging ethical issues relating to the translation industry: automation, workplace monitoring, and the challenge of crowdsourcing. The chapter shows that the translation industry, while sharing many of the ethical issues of any other sector, needs to be sustained by the development of an ethical reflection which is specific to the multifaceted reality of this rapidly-changing and global sector. 


\section{B. A SHORT HISTORY OF ETHICS IN THE TRANSLATION INDUSTRY}

This section places the growth of the translation industry in historical context. Globalisation was made possible by technological advances and by the neoliberal consensus since the 1970s, breaking down international trade tariffs. Translation was a key factor in facilitating globalisation, and its growth in the neoliberal era has influenced the key responsibility of language service providers (LSPs): to be profitable. Although the first LSPs appeared in the 1990s as part of a burgeoning translation and localisation industry (O'Hagan 1996), the almost exclusive profit-orientation was in line with the 1970's business mantra that 'the social responsibility of business is to increase its profits' (Friedman 1970, 122). This in turn influenced translation employment conditions to the extent that by 2012 freelance and contingent work practices had long overtaken that of standard employment (Pym et al. 2012). The profit motive is limited by the law, and Carroll (1991) suggests that additional but subordinate to legal limits are ethical responsibilities, obliging the company to behave fairly and to avoid harm. Interest in these ethical responsibilities, and in business ethics as a field, has grown since the 1980s, obliging management to 'respect the rights of employees, consumers, and society in general' (De George 2014, 502).

The literature on the social responsibilities of business evolved by extending the boundaries of companies' social engagement far beyond the satisfaction of their shareholders: since the publication of Freeman's stakeholder approach to strategic management (1984), any industry - including the translation industry - needs to face a new paradigm and to take into account the existence of different parties who can influence or are affected by the way a company sets and achieves its purpose.

As Drugan (2018) reports, from the 1990s a growing number of professional bodies and associations for translators were established, putting effort into creating codes of ethics for those working in this field. Around this time, translation and localisation research contributed 
work reflecting on their respective industries (e.g. O’Hagan 1996; Esselink 2000), although ethical reflection has been infrequent in Translation Studies, and appears to be a low priority in the translation industry.

Technological advances have meant that communication is increasingly digital, with more content now being created than is possible for humans to translate (Reinsel, Gantz, and Rydning 2018). The move to digital texts has affected translators' agency and ownership of resources, databases, and translations produced (Troussel and Debussche 2014). At the time of writing there are a number of coexisting modes of work and value models within the translation industry. While it is estimated that $70-80 \%$ of translators work full- or part-time on a freelance basis as part of what is known as the 'vendor model' of translation (Moorkens 2017), many still work as in-house translators, or translate as part of their role as what Pym et al. (2012) call paraprofessional translators. Institutions such as the European Union and the United Nations were considered particularly stable translation employers, but even the European Commission's Directorate General for Translation increasingly outsource work to the less-stable translation marketplace (Moorkens 2017).

If a translation employer's value proposition is based on lowering cost, this will mean that they necessarily have a highly transactional relationship with their translators, usually choosing the cheapest possible option. Bowker $(2019,460)$ has discussed the interrelated constraints of cost, time, and quality within a translation project, one of which will 'typically be compromised to some degree.' Pym, in particular, has considered this in his writing on translation ethics, noting that an employer may consider it worthwhile to compromise on quality while still producing a fit-for-purpose translation, moving any added cost in deciphering the text to the end user (Pym 2012, 146); or the purpose may require a highquality publishable text. In the latter case, there is a greater trust relationship inherent in the 
reliance of the client on the translator to produce a text that is consistently readable, accurate, and error-free (ibid. 146).

The push to reduce the cost of translation on the part of some employers involves retention of translation copyright ownership without payment for reuse, and maximising leverage using machine translation (MT). ${ }^{\mathrm{i}}$ Issues of ownership and copyright have long been part of translation ethics discussions (Venuti 1998), more recently with regard to reuse of translations for purposes that may not have been envisaged by the translator such as in training MT systems (Kenny 2011). The use of MT in the translation industry appears to be growing since the advent of neural MT, and Moorkens and Lewis (2019b) argue that widespread data dispossession and unilateral imposition of MT post-editing with related discounts may threaten the long-term sustainability of the translation industry in two ways: Firstly, in assuming that the ongoing reuse of data for which there can be several conflicting copyright claims can continue indefinitely, and secondly, by employing work practices that may discourage current and future translators. This is discussed further in Section C.

With regard to the future of the translation industry, this sector has been ahead of most others in terms of casualisation, globalisation, and digitalisation. While in other industries this has led to decreased employment, with technology gradually replacing some of the tasks that human beings used to perform, the headline figures in the translation industry seem to be less affected. The US Bureau of Labor Statistics (2019), for example, estimates that the number of translators and interpreters employed in the USA will increase by $19 \%$ in the decade 2018-2028, a growth rate beyond the predictions for many other industries. Practitioners in the field, such as Rechtman (2018), propose some reasons why Artificial Intelligence (AI)-based systems will not be able to replace human translators, citing subjectivity of language, artificial systems' lack of sense of humour, and automatic speech recognition technology's inability to follow and translate real-time speech. 
In light of this historical review, the next section illustrates how one might perform an ethical analysis of the translation industry and which specific ethical considerations need to be taken into account.

\section{ETHICS AND THE TRANSLATION INDUSTRY: REVIEWING ETHICAL CONSIDERATIONS}

Conducting an ethical analysis of an industry requires one to consider the purpose of this industry and whether the day-to-day company operations are aligned with or drift from its purpose. According to Melé (2019), there are different ways of looking at the purpose of a company: a) it can be oriented to the mere satisfaction of shareholders' interests (shareholder approach); b) it can enlarge its purpose taking into account the existence of different agents having interests in the activity of that company (stakeholder approach); c) it can aim at contributing to the common good of society (common good approach). A translation company setting its mission in line with the stakeholder or the common good approach does not, of course, ignore the interest of shareholders. However, going beyond the mere generation of profit helps with viewing the company as a community of people working together for a common purpose rather than a set of contracts that need to be respected. Indeed, ethics can be defined as a guide for human excellence, and business ethics as a guide for human excellence in business organisations (Melé 2019). In light of this definition, which is shaped around an Aristotelian conception of ethics, people achieve excellence when they are able to express their full potential as human beings, flourishing qua human beings; and a business achieves excellence when, through its activity, it contributes to the good of society. Any company operating in the translation industry enhances society by allowing people to understand each other and to extend the use of goods and services to populations where these 
goods and services would not be able to circulate without a common language used between the provider of the good or service and different intermediaries or the final users.

The literature on ethical issues experienced in the translation industry tends to revolve around the different actors who have an interest in the activity of the company rather than on the overall contribution of the translation industry to the good of society. For this reason, this section reviews existing literature related to different stakeholders of a translation company, and it concludes by highlighting possible paths to engage in a 'common good' approach to the purpose of the translation industry.

A company operating in this sector may focus on one or many language pairs and usually has a centralised management structure to interact - usually virtually within a projectsspecific network (Risku et al. 2013) - with a multitude of clients and translators, functioning as a channel between those who request the service and those who offer it. This means that a company in the translation industry has many stakeholders, whose identification would help to methodically assess the ethical issues that the industry faces.

Freeman defines a stakeholder in an organisation as 'any group or individual who can affect or is affected by the achievement of the organisation's objectives' $(2010,46)$. For the scope of this chapter, the most relevant stakeholders of a typical translation production network are taken into consideration. We do not explicitly mention some stakeholders who are typical of a company in any industry (such as people working in accounting or human resources) and restrict discussion to the stakeholders particular to the translation industry. The following figure visually describes internal and external stakeholders connected to an LSP.

<FIGURE 20.1 HERE>

Figure 20.1: Internal and external stakeholders in a typical translation production network 
The LSP stands at the centre, originating and connecting the network of internal and external stakeholders. Internally, owners, project managers, and in-house translators have interests in the activity of the LSP (together with other employees typical of any industry). Language software developers, freelance translators, clients, end users, and society are the external stakeholders of an LSP. The presence of society at large as an external stakeholder opens up the possibility of looking at the industry's contribution to the good of society, as we shall highlight in Section D.

The following five sub-sections cover different aspects involving LSP stakeholders: (i) the asymmetric relationship between translators and their employers, considering how that might affect the end user, (ii) how this results in unequal ownership of resources; (iii) the importance of sustaining translation as an attractive career option for translators and for society, (iv) resources for translators' ethical training, and (v) the importance of trust and accountability, drawing mostly on literature from outside Translation Studies.

\section{Disparities of Power}

At one end of a translation production network is the translator, usually freelance, who provides a service to the translation buyer that conforms to quality expectations, respecting the source text, the translation brief (if provided), and target-language reader requirements. The tendency towards freelance work in the translation industry has made translators reliant on ethical behaviour on the part of their employers due to the disparity in power inherent between organisations of different sizes. Outsourcing saves an employer the costs of statutory requirements such as holiday or sick leave, training, as well as office costs such as light, heat, hardware, software, desks, seating, and office space (Campbell, Watson, and Buchanan 2004). Freelance translators are particularly vulnerable when they deal exclusively with a 
single translation agency, a situation known as bogus self-employment. As such, they have little recourse if employers act in bad faith. Berardi (2015) highlighted the difficulty of collective action among distributed digital workers, although some groups have selforganised successfully, and others highlight poor or unethical employment practices such as non-payment, late payment, low rates, unilateral imposition of MT post-editing, and fake translation testing on online message boards, social media groups, and mailing lists. Abdallah (2010) reported several ways in which translators can protect their agency by attempting retribution or avoiding confrontation. This is unnecessary for many translators, of course, who have built up long-term trust relationships with their employers whereby their needs and concerns are considered and valued in a mutually beneficial relationship.

Where possible, Pym suggests that the translator should balance self-interest and cooperation, charging the 'highest rate that the client can risk paying' $(2012,151)$, with the caveat that the cooperation facilitated by the translator may impoverish one party (and thus he suggests loyalty to the weaker party), and that the cooperation may be so successful that the parties learn a lingua franca, rendering the translator unnecessary. The freedom for a freelance translator to act in their own best interests rather than within the constraints of bounded rationality depends on their relationship with those that hire or engage them, usually mediated via a project manager.

The translation project manager may work on a freelance or in-house basis. Their role is to agree the budget and timescale for a project, and to ensure that these are respected. While in some cases project management may be automated, it is common for the project manager (or a vendor manager reporting to them) to be the main point of contact for a translator and their main advocate within the network, subject to loyalty to their employer. At a similar level in the production hierarchy are direct employees who work in roles that relate to a project, 
without necessarily directly contacting the translators. These stakeholders are constrained by the practices of their employer when dealing with translators and clients.

Translation companies that outsource work vary massively in size from sole traders, cooperatives, or limited company operations employing a small number of people, where management may have a direct hand in individual projects, to larger companies and conglomerates who must focus on profit-making. This market fragmentation was highlighted by Dranch, Beninatto and Johnson (2019), who report that the top ten language service companies' total combined turnover surpassed US\$3.9 billion in 2018 . If the company is publicly traded, their fiduciary responsibility will be to reward shareholders within legal limits and while minimising harms to employees and society at large. They must minimise risk, perhaps ensuring that translators have indemnity insurance, and retain both clients and preferred employees. In publicly-traded companies that provide language services, the shareholder may be large or small, and while they may encourage corporate-social responsibility, they ultimately want return of investment and maximisation of profit. This is typically considered in the short rather than long term by lowering costs. The absence of a 'just balance in development' between all stakeholders and long- and short-term needs (Docherty et al. 2008, 4) may threaten the sustainability of the translation industry and deprive the final stakeholder - society at large - of access to reliable multilingual information.

\section{Ownership of resources}

The FIT (International Federation of Translators) Translator's Charter (FIT 1963/1994) states that a translation, as 'a creation of the intellect, shall enjoy the legal protection accorded to such works,' including the 'same privileges as the author of the original work.' In practice, however, the rights of translators over translated material and translation 
repositories are not clear. In a review of translation copyright Troussel \& Debussche (2014) assert that translators have legal rights to copyright ownership, subject to the rights of original authors and depending on the jurisdiction based on the Berne Convention, and within the European Union, possible further rights as creators and maintainers of a database when using translation memories (TMs). Depending on their creative input and the type of source text, such a claim of ownership could be strengthened, and a further translation copyright may be asserted that would require the translator's permission (and possible royalty payments) for retranslation based on their translated text.

However, it is common practice in the translation industry for translators to return TMs via the project manager to their employers, retaining no ownership over the TM or the final translation. This means that translators have no control over how their work is repurposed, nor for the type of material translated while leveraging their work in secondary and tertiary use. New use cases continually appear for repurposing all data, translation data included, that were not previously envisaged (Moorkens 2017). The industry perspective continues to be that copyright is generally owned by the end client, with TMs retained by the translation provider for leveraging by any translator employed so as to minimise cost. Due to the growing and insatiable demand for human-created data in translation and other areas for training data for machine learning, this data is increasing in value. Moorkens and Lewis (2019b) note that in retaining the data, translation employers take on responsibility for storage and data security, with operational and legal risks in case of a cyberattack. However, they suggest a move to translator ownership of this data with royalty payments to translators as an option for improving the power balance and sustainability of the translation industry.

Even if the issues related to ownership of resources can seem to be of a legal nature, ethics are very much involved, as a violation of rights or contracts is in clear contrast with the virtue 
of justice, which can be defined as the consistent intention to give each person what is due to them (Melé 2019).

\section{Sustaining Employment in the Translation Industry}

In order to take ethical considerations into account, and to improve the agency of translators, Abdallah $(2014,13)$ puts forward a three-dimensional quality model, which could take into account not only the product and process of translation, but also the social quality, which includes translators' 'relations to the rest of society and their relations and interaction pertaining to the work that is collectively produced.' She believes that by taking the relationship with the rest of society into account, and by maximising ethical employment practices, translation work could be made more attractive and sustainable. This is a concern voiced more and more often at translation conferences and events; various surveys and articles have highlighted translators leaving the industry due to low rates, stress of tight deadlines, imposition of post-editing work with low-quality MT with a mandatory discount, and difficulties in getting paid (Abdallah 2010; EC/CIOL/ITI 2017).

Due to the high number of translators (Pym et al. (2012) estimated this to be 330,000 worldwide) and their varied modes of work, the number of people leaving the industry is difficult to estimate. Even without this information, the social quality of a translation production network appears to be undervalued. Lagoudaki (2008) described how translators' requirements for translation editing interface design were subordinate to those of their employers, and ten years later translators cited similar dissatisfaction with translation tools (Moorkens and O'Brien 2017). Without an obvious return of investment, the arguments to tailor tools or workflows for translators tend not to filter through the production network.

A deficit of translators would also bring about a lack of translation data for training of MT systems. Neural MT requires huge amounts of bilingual data for training, with updates 
needed for changes in language and terminology. While the most widely-translated languages are currently reasonably well served for data to maximise MT quality, the majority are still short of enough translation data to create high-quality MT systems. Even the best-performing systems have shown evidence of standardisation and a loss of linguistic diversity in their output (Vanmassenhove, Shterionov, and Way 2019). Research into unsupervised MT systems that can be trained on monolingual data have shown some positive results (Artetxe, Labaka, and Agirre 2019), but nonetheless, the ongoing collection and reuse of translation data for MT training is necessary for systems to produce current and maximum-quality results.

Moorkens and Lewis (2019b) consider whether the industry is following a sustainable trajectory, or whether changes are necessary to improve translator wellbeing and to address issues regarding ownership of translation resources (see section that follows). They cite the International Labour Organisation's substantive elements of Decent Work (Ferraro, Pais, and Rebelo Dos Santos 2015) and argue that these are not reflective of the translation occupation for many freelancers. Moorkens (2020) asserts the need to fulfil motivation and satisfaction factors within sustainable work systems. If translators are exiting, yet the demand for translators is growing, sustainability must be a concern. Cronin (2017) believes that, as translators' work is not sufficiently valued nor remunerated, translators would be better to advocate the large-scale societal changes required to facilitate global environmental sustainability (see section that follows). Pym (2004) wrote that the argument for more translation is not always justifiable, such as when the target text is of insufficient worth to justify the effort, implicitly criticising the constant hunger for growth in the translation industry.

At present, international and national translator organisations (such as FIT) perform valuable lobbying on the part of translators and work on protecting the sector. The FIT 
Translator's Charter (FIT 1963/1994) and the United Nations Educational, Scientific and Cultural Organization (UNESCO) Recommendation on the Legal Protection of Translators and Translations and the Practical Means to improve the Status of Translators (UNESCO 1976) recommend rates of pay and employment protection for translators equivalent to other professions, along with copyright ownership of translated works. These recommendations are more relevant than ever, although their effectiveness is difficult to evaluate. Translator organisations also offer valuable fora for discussion, advice, and professional development options for translators. The latter are discussed in detail in the following section.

\section{Resources for Translators: Ethical Training as Continuing Professional}

\section{Development?}

National associations provide their members with opportunities for continuing professional development (CPD), and often offer courses, readings, conferences, seminars and workshops, although few of these tend to focus specifically on ethics. A more systematic approach to the professional development of the profession would make these standalone efforts part of an integral project. In other industries, a great deal of attention is given to ethical training of workers. Many of the resources for CPD of translators are intended to develop their career as professional translators and self-made entrepreneurs (e.g. McKay 2006). One exception is the American Translators Association (ATA), which offers an online

ethics module as an educational requirement (https://www.atanet.org/certification/online_ethics_overview.php).

There is debate in academia about the effectiveness of training in ethics: for example, in the field of business ethics education, Hartman inquired how anyone can 'expect to make a business student a good person with one course in one semester?' $(2013,189)$. The same can be argued for ethical training for translators and the need for transformative change in the 
way that ethics is perceived across this industry: ethics is not a mere list of dos and don'ts, nor the mere application of a code of conduct, it is rather a guide for excellence in human behaviour (Melé 2019). If ethics is perceived in this way, translators should realise that training in ethics is not a box to tick or an additional line to their curriculum, but rather an instrument to fully develop as excellent translators and excellent human beings.

In the case of the translation industry, it would be worth enhancing the development of ethical training for two main reasons: Firstly, it would help raise the ethical standards of the profession on the side of both employers and freelancers. Secondly, it would provide translators with the intellectual tools to understand how developing the virtues of a good translator will also contribute to their own personal flourishing. Drugan and Megone (2011) comment on the absence of systematic training in ethics at the level of academic education and suggest the integration of ethics across the Translation Studies curriculum, using case studies as a teaching tool to stimulate discussion and to train learners in ways to solve concrete ethical dilemmas typical of the profession.

At present, particularly in translator associations, the focus in CPD is on good business practices and field specialisation, which has proved to be key for several very successful translators. Specialisation, however, needs to be combined with responsiveness, professionalism, and trust-building in interactions with translation buyers (Durban 2011): this will help to enhance the relationship between the LSP and its internal and external stakeholders, also cultivating excellence within the profession.

\section{Trust in the Translation Industry}

In general, a relationship of trust is established in an interaction or economic exchange when one of the parties exposes their vulnerability to the other and relies on the positive expectations towards the intentions of the other (Rousseau et al. 1998). In his work on 
translation ethics, Chesterman asks 'why should translators be loyal to their profession, why should they be accountable to these various other participants in the communication situation? My answer would be: because of the overriding value of trust' $(1997,181)$.

Given the way the translation industry is currently structured, it is not only the individual translators that need to ensure loyalty to their profession and accountability towards the other agents involved in the translation network, as Chesterman affirms, but also the companies operating in this sector need to build trust for their business to be successful. The academic literature on translation and trust from an organisational point of view is not as developed as the academic literature that considers the relationship of trust between the translator and the other actors in the translator network, in one-to-one relationships. This distinction between trust on a personal level and on an institutional level is explored by Rizzi, Land and Pym (2019) with reference to translation (also adding the perspective of 'regime-enacted' trust). A seminal contribution in the exploration of trust at an organisational level by Abdallah and Koskinen (2007) refers to the translation industry as network-based. With the caveat of the lack of support from a more extended body of literature, it can be argued that those relationships of trust highlighted by existing literature in Translation Studies from an individual point of view can be analysed, mutatis mutandis, in the perspective of the organisation. Following the stakeholder approach that this chapter suggests for the analysis of the translation industry, it can be argued that a company in the translation industry needs to establish relationships based on trust with all the stakeholders involved in its network.

From the point of view of an individual translator, Chesterman presents this multistakeholder view on trust, listing the different actors involved in the trust relationship with the translator:

The translator also needs to trust the original writer, and also the commissioner of the translation: there must be a trust that the translation itself 
is worth doing. Translators must also trust that their readers will read the translation in good faith, that their readers in turn will trust that there is "something there" in the translation that makes it worth reading. It is, in fact, not only the translator that must trust, but also the other parties to the translating act: readers, plus of course the commissioner of the translation, the publisher, and also the original writer (if still alive, of course). Translational trust works both ways (Chesterman 1997, 180).

Chesterman also argues that trust is 'the value governing the accountability norm' (1997, 180). He defines this accountability norm, explaining that 'a translator should act in such a way that the demands of loyalty are appropriately met with regard to the original writer, the commissioner of the translation, the translator himself or herself, the prospective readership and any other relevant parties' (Chesterman 1997, 68).

In deploying all the multi-faceted relationships of trust implied in the work of the translator, Chesterman's contribution can be re-read as a building block of the contemporary translation industry. Trust is at the basis of the relationship between all stakeholders, frequently mediated by a company, which needs to enter these trust-based relationships and strengthen them. Adding a layer to this process can actually add complexity, without adding economic expense if trust is built (Pym 2004). Conversely, processes related to translation within a company become slower and more expensive due in particular to lack of trust and information asymmetry (Chan 2008). For example, clients with no expertise in the target language can either outsource to verify the accuracy of a translation, or they can just trust the translator because of their reputation or the reputation of the intermediary agency. As in any other industry, mistrust bears a cost, whereas 'to build trust is also to reduce transaction costs' (Pym 2004, 5). Pym links trust primarily to its role of reducing complexity. Reduced complexity and increased trust contribute to lowering overall costs, making trust the 'highest 
virtue to be sought in translators' based on the value in its 'role as the prime mechanism for reducing complexity’ (Pym 2004, 11).

Mistrust can also generate other costs related to the translators' working conditions. The growing fear of piracy and leaks, primarily of audiovisual and entertainment materials, adds constraints on translators, who often find themselves outside of a circle of trust, having to work with pre-release material. This may result in non-disclosure agreements, and in working conditions where the need for secrecy impinges on the ability to produce a high-quality target text. Hubscher-Davidson (see chapter in this handbook) notes the ethical stress for translators in situations when professional deontological ethics and business ethics are at cross-purposes.

With specific reference to the translation industry, Abdallah and Koskinen discuss how trust can be managed within the industry, and they note this may be particularly complex due to 'the geographic distance between the intermediary agency and the translators, as well as by the sheer number of translators needed for a steady output in several language pairs' (2007, 681). The level of trust needs to be even higher when the end users of the products delivered by the translation industry are especially vulnerable. With regard to translation and children's literature, Oittinen (2006) specifically addresses the ethical concerns related to the activity of the translator catering for the youngest possible public of readers. She interestingly refers to an Aristotelian conception of ethics and the way human beings strive to achieve personal flourishing (Aristotle 2000) in order to assess the ethics of translation in this specific context, and discusses how the choice of a foreignisation or domestication may be viewed as ideological imposition of the adult's view on children (Oittinen 2006).

Avenues for further research in trust and the translation industry might consider the application to translation of a study conducted by van der Werff, Real, and Lynn (2018). The authors compared traditional models of trust with trust in technology systems. Given the way that the translation industry is structured with intertwined and overlapping contributions of 
human translators and AI-based systems, it can be potentially argued that the translation industry currently combines the dimensions entailed in both the traditional trust model and the trust in technology systems (van der Werff, Real, and Lynn 2018, 393). As reported by van der Werff et al. (2018), the dimensions of traditional trustworthiness are ability, benevolence, integrity, competence, benevolence, honesty/integrity, and predictability, while the dimensions entailed in technology systems are performance, purpose/helpfulness, process/predictability, functionality, helpfulness and reliability. It would be worth exploring the combination of these dimensions in the translation industry, given the evolution of the translation industry business model - which in many cases has completely shifted to the online market - and of the translation technique itself.

\section{NEW FRONTIERS FOR THE ETHICS OF THE TRANSLATION INDUSTRY}

This topical section reviews the way the translation industry addresses environmental concerns and reflects on the ethical implication of the introduction of AI-based systems throughout different processes typical of the translation industry. Moreover, a special focus is dedicated to the opportunity to develop those traits that are specifically human in the translation process, such as human wisdom, considering the massive introduction of new technologies.

\section{Environmental Sustainability in the Translation Industry}

Cronin $(2017,6)$ highlights translation's place in increasingly unsustainable energy dependency, with localisation in particular associated with an 'ideology of boundless growth'. Translation technology relies on the ICT industry, with its use of mined rare metals and deserved reputation for poor recycling and polluting (Cronin 2017). Increased communication requires vast rollouts of fibre optic cabling and storage for the estimated 175 
ZB of data held by 2025 , with $49 \%$ expected to be held in cloud computing environments (Reinsel, Gantz, and Rydning 2018). Neural MT is particularly computationally expensive, requiring powerful GPUs (Graphical Processing Units) for training and large amounts of power. Strubell, Ganesh, and McCallum (2019) estimate that training one large transformer neural network model will produce almost five times the $\mathrm{CO}^{2}$ output of a car (including fuel) during its full lifetime.

Cronin believes that the only solution to this unsustainable consumption is a 'Great Transition' away from the ideal of continuous growth with translation central to such a move on a societal scale, based on solidarity with global and future humans. He pushes against the utopian idea of mutual intelligibility that was the basis of Weaver's (1949) initial ideas for MT, suggesting that diverse linguistic spaces are more resilient and viable. Following such a transition, translation would revert to a craft, facilitating artistic, literary, spiritual, or creative work, rather than 'the auxiliary of material goods based on wealth creation' (Cronin 2017, 117). With respect to industry, this means taking a broad, imaginative, and ethical view of the enterprise landscape that fits with the perspective of Docherty et al. (2008, 4), who advocate work within sustainable systems 'aimed at the regeneration of... human, social, material and natural resources' for the benefit of future generations.

\section{AI and the Future of Translation Work: Machine Translation and Human Wisdom}

The hype about neural MT (NMT) (Castilho et al. 2017) has brought existential angst to the fore for translators (Vieira 2018). On the face of it, the large and growing amounts of translation required should mean that both human and machine translation have a strong outlook. Employment in translation continues to grow (Bureau of Labor Statistics 2016) alongside increased MT throughput (Google 2016), and MT continues to rely on humans for its data and evaluation (Kenny 2011). 
However, the translation industry has enthusiastically taken on MT as a productivity tool (Lommel and DePalma 2016), with the technology often imposed on translators rather than introduced in consultation (Cadwell, O'Brien, and Teixeira 2018), and new use cases being found for successful integration of raw and post-edited MT where automation had previously been considered unwise or risky (Moorkens 2017). This imposition of automation, along with digital dispossession and predictions of technological unemployment in the media, tends to add to negative perceptions from translators - and trainee translators - of their prospects. These perceptions are common to other sectors which are affected by machine learning, where data is gathered at scale and repurposed for training. As newer translation tools, whether locally installed or using a browser interface, use cloud-based storage, there are additional concerns about workplace monitoring and aggregation of translation and personal data.

Workplace monitoring is becoming more prevalent in general to avoid misuse of company time and resources. Moore and Robinson report the spread of monitoring to contingent and creative workers, writing that 'workers are now being asked to measure our own productivity and health and well-being in art-houses and warehouses alike' $(2016,2774)$. User activity data may now be recorded within several commercial translation tools. Product quality monitoring is still more common in the translation industry, with samples of specialised translation work often measured using error typologies (Lommel 2018). The sample size, or whether work is sampled at all, may differ based on the trust relationship with the translator, and poor results in these evaluations may affect future employment prospects (Koo and Kinds 2000).

With the aim of obtaining a smoother workflow - which can also be constantly tracked and monitored - the translation industry is moving to cloud translation platforms that combine the power of cloud computing with technology specialised in language processing. 
These interfaces can 'realise collaborative translation functions, organising multiple spatially distributed translators to complete one translation task' (Yan Ren 2015). The move to cloud computing systems is likely to cause some of the ethical issues found in other industries using cloud computing technology, such as the 'problem of many hands,' when a single person cannot be identified or held responsible when a problem occurs, or issues related to ownership and privacy that are already problematic in the translation industry (Timmermans et al. 2010). Garcia (2015), on the other hand, believes that cloud-mediated interactions could help with translator recruitment, and Benotmane (2019) predicts that the use of quality monitoring via the cloud will have an equalising effect, highlighting the quality of good translators who may not market themselves successfully, and assuring trust and quality in online marketplaces where identity theft and lying about translation skills have previously caused problems (Pym, Orrego-Carmona, and Torres-Simón 2016).

Online marketplaces include those where professional translators meet and jobs are offered, the general purpose crowdwork platforms, and many in between. Crowdsourced translation is community-based and works thanks to the existence of the internet. Unlike machine learning, it does not need a specific technology designed for the purpose of translation, but only a functioning network. Katan $(2016,12)$ has predicted that by 2025 nonprofessionals will account for 'most social media and much audiovisual translation,' and in his 2008 survey, amateur translators, especially those with subject-specific knowledge from other fields, were considered the biggest threat to the profession by 388 professional and paraprofessional translator and interpreter respondents (Katan 2009). Anastasiou and Gupta define crowdsourcing as 'the process by means of which organisations can tap into the wisdom of their dedicated external community and use the wisdom for their benefit, i.e. with low cost, for more languages, and within the specified time frame' $(2011,638)$. The use of the word 'wisdom' is interesting here, as in the domain of ethics and technology there is a 
debate about whether human wisdom can or cannot be substituted and automated. Vallor (2016; 2017), in light of the analysis of the common characteristics of wisdom in different ethical traditions, concludes that wisdom is considered 'as more than knowledge, intelligence, or expert skill.' Rather, it is 'considered as a manner of living, a life which regulates and cultivates itself in the light of those ends it has chosen or grasped as ultimate in value, that is, in light of life conceived as whole' (Vallor 2017, 176). This is relevant to human contribution to the activity of translation. Chesterman (2006) goes as far to include translation in the realm of activities that the moral philosopher Alasdair MacIntyre (2007) describes as 'practices.' MacIntyre defines a practice as:

Any coherent and complex form of socially established cooperative human activity through which goods internal to that form of activity are realised in the course of trying to achieve those standards of excellence which are appropriate to, and partially definitive of, that form of activity, with the result that human powers to achieve excellence, and human conceptions of the ends and goods involved, are systematically extended (2007[1981], 187).

As Chesterman notes, in this definition cooperation prevails on competition, and the key word that frames the context of the activity is excellence. Moreover, following MacIntyre (2007), the practice is embedded in a tradition which the practitioners continue to enhance. There is a narrative in which the translators participate as protagonists, bringing in their desire to be excellent qua professionals and qua human beings. The assertion here is that, even if automation will be able to replace some of the 'tasks' of translators, it will never replace this desire for personal flourishing and the professionalism and passion that each translator adds to the long tradition of this persistently necessary job. These considerations open avenues for further research in the ethics of the translation industry: it is worth exploring the characterization of the specific goods that the translation industry brings to 
society, and of the virtues that human translators need to develop in the current heavily automated scenario.

The question for the future of the translation industry is whether to retract as a move to global environmental sustainability, to continue as at present, pushing more translators into post-editing, or to aim for an empowering middle ground that follows the intention of Kay in his Proper Place of Men and Machines in Language Translation (1980), wherein machines process quantity while 'human translators will make decisions, give advice, gain trust, and transmit quality’ (Pym 2012, 145).

\section{E. CONCLUSION: A SUMMARY AND IMPLICATIONS}

This chapter reviews existing literature on the ethics of translation industry, first placing translation in the context of the global economy and growing consideration of corporate social responsibility and business ethics at the end of the 21 st century. The translation industry in general appears to consider business ethics subordinate to the profit motive, and receives little push-back from translators, who are often not in a position to maximise their agency due to disparities of power. In examining the relationships and motivations within a translation production network, we identify a number of stakeholders and consider their concerns and responsibilities. In analysing training options for translators, ethical training is lacking, but this could contribute to the personal flourishing of a translator as a good professional and as a person, and to trust-building. Several freelance translators have built high-trust relationships with their employers, and thus enjoy better conditions with respect to payment, monitoring, and data ownership than many of their peers. For others, the various pressures of freelance translation work may lead them to consider leaving the industry. This brings concerns about the sustainability of the industry, prominently discussed by Cronin 
(2017), who believes that a major shift from industrial translation is required as part of a global shift to cut consumption.

This is one option when considering the future of translation work, as AI, workplace monitoring, and crowdsourcing continue to change the nature of the role of a translator. Another option is to continue along the current trajectory with more translators pushed into unsatisfying work and struggling for secure payment. A third way follows the suggestion of Kay (1980), letting machines do the heavy lifting while humans attempt to flourish with creative, interesting, and curatorial work.

\section{F. LIST OF RELATED TOPICS IN THIS VOLUME (BASED ON THE CHAPTER LIST PROVIDED)}

\section{G. REFERENCES}

Abdallah, Kristiina. 2010. "Translator's Agency in Production Networks." In Translator's Agency, edited by Tuija Kinnunen and Kaisa Koskinen, 11-46. Tampere: Tampere University Press.

. 2014. "Social Quality: Key to Collective Problem Solving in Translation Production Networks." Proceedings of the 6th Riga Symposium on Pragmatic Aspects of Translation, 5-18.

Abdallah, Kristiina, and Kaisa Koskinen. 2007. "Managing Trust: Translating and the Network Economy." Meta: Journal des traducteurs 52 (4): 673. https://doi.org/10.7202/017692ar.

Anastasiou, Dimitra, and Rajat Gupta. 2011. "Comparison of Crowdsourcing Translation with Machine Translation.” Journal of Information Science 37 (6): 637-59. https://doi.org/10.1177/0165551511418760.

Aristotle. 2000. Nicomachean Ethics. Cambridge Texts in the History of Philosophy. Cambridge, U.K. ; New York: Cambridge University Press.

Artetxe, Mikel, Gorka Labaka, and Eneko Agirre. 2019. "An Effective Approach to Unsupervised Machine Translation.” ArXiv:1902.01313 [Cs], February. http://arxiv.org/abs/1902.01313.

Benotmane, D. 2019. "Translation Quality Is Risk Avoidance." Paper Presented at Hello World, Germany's Software Localization Conference, Hamburg, Germany. 
Berardi, Franco. 2015. And: Phenomenology of the End: Sensibility and Connective Mutation. Semiotext(e) Foreign Agents Series. South Pasadena, CA: Semiotext(e).

Bowker, Lynne 2019. In The Routledge Handbook of Translation and Technology, edited by Minako O'Hagan, 453-68. Abingdon: Routledge.

Bureau of Labor Statistics. 2019. Occupational Outlook Handbook, 2018-19 Edition: Interpreters and Translators. Washington, D.C.: US Department of Labor.

Cadwell, Patrick, Sharon O'Brien, and Carlos S. C. Teixeira. 2018. "Resistance and Accommodation: Factors for the (Non-) Adoption of Machine Translation Among Professional Translators." Perspectives $26 \quad$ (3): 301-21. https://doi.org/10.1080/0907676X.2017.1337210.

Campbell, Iain, Ian Watson, and John Buchanan. 2004. "Temporary Agency Work in Australia (Part I).” In International Perspectives on Temporary Work, edited by John Burgess and Julia Connell, 129-44. Abingdon: Routledge.

Carroll, Archie B. 1991. "The Pyramid of Corporate Social Responsibility: Toward the Moral Management of Organizational Stakeholders." Business Horizons 34 (4): 39-48. https://doi.org/10.1016/0007-6813(91)90005-G.

Castilho, Sheila, Joss Moorkens, Federico Gaspari, Iacer Calixto, John Tinsley, and Andy Way. 2017. "Is Neural Machine Translation the New State of the Art?" The Prague Bulletin of Mathematical Linguistics 108 (1): 109-20. https://doi.org/10.1515/pralin2017-0013.

Chan, Andy Lung Jan. 2008. "Information Economics, The Translation Profession and Translator Certification." Universitat Rovira i Virgili, PhD Thesis.

Chesterman, Andrew. 1997. Memes of Translation: The Spread of Ideas in Translation Theory. Benjamins Translation Library, v. 22. Amsterdam; Philadelphia: J. Benjamins.

2006. "Questions in the Sociology of Translation." In Translation Studies at the Interface of Disciplines, edited by João Ferreira Duarte, Alexandra Assis Rosa, and Teresa Seruya, 9-27. Benjamins Translation Library, EST Subseries, v. 68. Amsterdam ; Philadelphia: J. Benjamins Pub. Co.

Cronin, Michael. 2012. "Translation and Globalization." In The Routledge Handbook of Translation Studies, 491-502. Routledge. https://doi.org/10.4324/9780203378816. . 2017. Eco-Translation: Translation and Ecology in the Age of the Anthropocene. New Perspective in Translation and Interpreting Studies. London; New York: Routledge, Taylor \& Francis Group.

De George, Richard T. 2014. Business Ethics. 7. ed., Pearson new internat. ed. Pearson Custom Library. Harlow, Essex: Pearson.

Docherty, Peter, Mari Kira, A. B. (Rami) Shari. 2008. "What the world needs now is sustainable work systems". In Creating Sustainable Work Systems: Developing Social Sustainability, edited by Peter Docherty, Mari Kira, A. B. (Rami) Shari, 1-22. Abingdon: Routledge.

Dranch, Konstantin, Renato Beninatto, and Tucker Johnson. 2019. "Nimdzi 100." nimdzi Market Reports.

Drugan, Joanna. 2017. "Ethics and Social Responsibility in Practice: Interpreters and Translators Engaging With and Beyond the Professions." The Translator 23 (2): 12642. https://doi.org/10.1080/13556509.2017.1281204.

. 2018. "Ethics." In The Routledge Handbook of Translation and Philosophy, edited by Piers Rawling and Philip Wilson, 1st ed., 243-55. Routledge. https://doi.org/10.4324/9781315678481-16. 
Drugan, Joanna, and Chris Megone. 2011. "Bringing Ethics into Translator Training: An Integrated, Inter-Disciplinary Approach." The Interpreter and Translator Trainer 5 (1): 183-211. https://doi.org/10.1080/13556509.2011.10798817.

Durban, Chris 2011. Translation: Getting It Right. A Guide to Buying Translation. https://www.atanet.org/publications/getting_it_right.php.

EC/CIOL/ITI. 2017. "UK Translator Survey: Final Report." https://ec.europa.eu/unitedkingdom/sites/unitedkingdom/files/ukts2016-final-reportweb_-_18_may_2017.pdf.

Esselink, Bert. 2000. A Practical Guide to Localization. New and totally rev. ed. Language International World Directory 4. Amsterdam: Benjamins.

Ferraro, Tânia, Leonor Pais, and Nuno Rebelo Dos Santos. 2015. "Decent Work: An Aim for All Made by All." International Journal of Social Sciences IV (3): 30-42. https://doi.org/10.20472/SS2015.4.3.003.

FIT, 1963. 1994. "Translator's Charter." www.fit-ift.org/?p=251.

Freeman, R. Edward. 1984. Strategic Management: A Stakeholder Approach. Pitman Series in Business and Public Policy. Boston: Pitman.

2010. Strategic Management: A Stakeholder Approach. Cambridge: Cambridge University Press. https://doi.org/10.1017/CBO9781139192675.

Friedman, Milton. 1970. "The Social Responsibility of Business Is to Increase Its Profits." The New York Times Magazine, September 13, 1970.

Garcia, Ignacio. 2015. "Cloud Marketplaces: Procurement of Translators in the Age of Social Media." The Journal of Specialized Translation, no. 23: 18-38.

Google. 2016. "Machine Learning Office Hours." Google IO.

Hartman, Edwin. 2013. Virtue in Business: Conversations with Aristotle. Business, Value Creation, and Society. Cambridge: Cambridge University Press.

Katan, David. 2009. "Occupation or Profession: A Survey of the Translators' World." Edited by Rakefet Sela-Sheffy and Miriam Shlesinger. Translation and Interpreting Studies 4 (2): 187-209. https://doi.org/10.1075/tis.4.2.04kat.

. 2016. "Translation at the Cross-Roads: Time for the Transcreational Turn?" Perspectives 24 (3): 365-81. https://doi.org/10.1080/0907676X.2015.1016049.

Kay, Martin. 1980. The Proper Place of Men and Machines in Language Translation (Report CSL- 80-11). Palo Alto, CA: Xerox Corporation.

Kenny, Dorothy. 2011. "The Ethics of Machine Translation." New Zealand Society of Translators and Interpreters Annual Conference.

Koo, Siu Ling, and Harold Kinds. 2000. "A Quality-Assurance Model for Language Projects." In Translating Into Success: Cutting-Edge Strategies for Going Multilingual in a Global Age, edited by Robert C. Sprung and S. Jaroniec, XI:147-57. Amsterdam: John Benjamins Publishing Company. https://doi.org/10.1075/ata.xi.16koo.

Lagoudaki, Elina 2008. Expanding the Possibilities of Translation Memory Systems. PhD diss., London: Imperial College.

Lommel, Arle, and Donald A. DePalma. 2016. Europe's Leading Role in Machine Translation. Common Sense Advisory Report.

Lommel, Arle. 2018. "Metrics for Translation Quality Assessment: A Case for Standardising Error Typologies." In Translation Quality Assessment, edited by Joss Moorkens, Sheila Castilho, Federico Gaspari, and Stephen Doherty, 1:109-27. Cham: Springer International Publishing. https://doi.org/10.1007/978-3-319-91241-7_6.

MacIntyre, Alasdair C. 2007. After Virtue: A Study in Moral Theory. 3rd ed. Notre Dame, Ind: University of Notre Dame Press. 
McKay, Corinne. 2006. How to Succeed as a Freelance Translator. 1st ed. U.S.: Two Rat Press.

Melé, Domènec. 2019. Business Ethics in Action: Managing Human Excellence in Organizations. 2nd ed. Red Globe Press.

Moore, Phoebe, and Andrew Robinson. 2016. "The Quantified Self: What Counts in the Neoliberal Workplace." New Media \& Society 18 (11): 2774-92. https://doi.org/10.1177/1461444815604328.

Moorkens, Joss. 2017. "Under Pressure: Translation in Times of Austerity." Perspectives 25 (3): 464-77. https://doi.org/10.1080/0907676X.2017.1285331.

—. 2020. "“"A tiny cog in a large machine": Digital Taylorism in the Translation Industry." Translation Spaces 9 (1).

Moorkens, Joss, and David Lewis. 2019a. "Copyright and the Reuse of Translation as Data." In The Routledge Handbook of Translation and Technology, edited by Minako O'Hagan, 469-81. Abingdon: Routledge.

2019b. "Research Questions and a Proposal for the Future Governance of Translation Data." Journal of Specialised Translation 32.Moorkens, Joss, and Sharon O’Brien. 2017. "Assessing User Interface Needs of Post-Editors of Machine Translation." In Human Issues in Translation Technology, edited by Dorothy Kenny, 109-30. Abingdon: Routledge.

Nord, Christiane. 1997. Translating as a Purposeful Activity. Functionalist Apporaches Explained. Manchester: St. Jerome.

O'Hagan, Minako. 1996. The Coming Industry of Teletranslation: Overcoming Communication Barriers Through Telecommunication. Clevedon: Multilingual Matters Ltd. http://search.ebscohost.com/login.aspx?direct=true \&scope $=$ site $\& d b=$ nlebk $\& d b=$ nlabk $\& A N=16702$.

Oittinen, Riitta. 2006. "No Innocent Act: On the Ethics of Translating for Children." In Children's Literature in Translation: Challenges and Strategies, edited by Jan van Coillie and Walter P. Verschueren, 61-78. Manchester, UK: Routlegde.

Pym, Anthony, David Orrego-Carmona, and Esther Torres-Simón. 2016. "Status and Technology in the Professionalisation of Translators: Market Disorder and the Return of Hierarchy." Journal of Specialised Translation 25 (33-53).

Pym, Anthony. 2004. "Propositions on Cross-Cultural Communication and Translation." Target 16 (1): 1-28. https://doi.org/10.1075/target.16.1.02pym.

2012. On Translator Ethics: Principles for Mediation Between Cultures. Benjamins Translation Library, v. 104. Amsterdam; Philadelphia: John Benjamins Pub. Co.

Pym, Anthony, François Grin, Claudio Sfreddo, and Andy L. J. Chan. 2012. The Status of the Translation Profession in the European Union. Luxembourg: Publications Office of the European Union. http://ec.europa.eu/dgs/translation/publications/studies/translation_profession_en.pdf.

Rechtman, Jonathan. 2018. “AI Won't Replace Human Translators Yet. Here Are 3 Reasons Why." World Economic Forum Online, October. https://www.weforum.org/agenda/2018/10/3-reasons-why-ai-wont-replace-humantranslators-yet/.

Reinsel, David, John Gantz, and John Rydning. 2018. "The Digitization of the World: From Edge to Core." IDC White Paper. https://www.seagate.com/www-content/ourstory/trends/files/idc-seagate-dataage-whitepaper.pdf.

Risku, Hannah, Nicole Rossmanith, Andreas Reichelt, and Lukas Zenk. 2013. "Translation in The Network Economy: A Follow-Up Study." In Tracks and Treks in Translation Studies: Selected Papers from the EST Congress, Leuven 2010, edited by Catherine 
Way, Sonia Vandepitte, Reine Meylaerts, and Magdalena Bartłomiejczyk, 29-48. Amsterdam: John Benjamins.

Rizzi, Andrea, Birgit Lang, and Anthony Pym. 2019. What Is Translation History?: A TrustBased Approach. Palgrave Macmillan. https://doi.org/10.1007/978-3-030-20099-2.

Rousseau, Denise M., Sim B. Sitkin, Ronald S. Burt, and Colin Camerer. 1998. "Not So Different After All: A Cross-Discipline View Of Trust." Academy of Management Review 23 (3): 393-404. https://doi.org/10.5465/amr.1998.926617.

Strubell, Emma, Ananda Ganesh, and Andrew McCallum. 2019. "Energy and Policy Considerations for Deep Learning in NLP." Proceedings of the 57th Annual Meeting of the Association for Computational Linguistics (ACL).

Timmermans, Job, Bernd Carsten Stahl, Veikko Ikonen, and Engin Bozdag. 2010. "The Ethics of Cloud Computing: A Conceptual Review." In 2010 IEEE Second International Conference on Cloud Computing Technology and Science, 614-20. Indianapolis, IN, USA: IEEE. https://doi.org/10.1109/CloudCom.2010.59.

Troussel, Jean-Christophe, and Julien Debussche. 2014. Translation and Intellectual Property Rights (Report by Bird \& Bird for the European Commission DG Translation). Luxembourg: Publications Office of the European Union.

Tymoczko, Maria. 2007. Enlarging Translation, Empowering Translators. Manchester, UK: St. Jerome Pub.

UNESCO. 1976. Recommendation on the Legal Protection of Translators and Translations and the Practical Means to Improve the Status of Translators. Paris.

Vallor, Shannon. 2016. Technology and the Virtues: A Philosophical Guide to a Future Worth Wanting. New York, NY: Oxford University Press.

. 2017. "AI and the Automation of Wisdom." In Philosophy and Computing, edited by Thomas M. Powers, 128:161-78. Cham: Springer International Publishing. https://doi.org/10.1007/978-3-319-61043-6_8.

Van Wyke, Ben. 2012. "Translation and Ethics." In The Routledge Handbook of Translation Studies, 548-60. Abingdon: Routledge. https://doi.org/10.4324/9780203102893.ch40.

Vanmassenhove, Eva, Dimitar Shterionov, and Andy Way. 2019. "Lost in Translation: Loss and Decay of Linguistic Richness in Machine Translation." Proceedings of MT Summit XVII, 222-32.

Venuti, Lawrence. 1998. The Scandals of Translation. Abingdon: Routledge.

Vieira, Lucas Nunes. 2018. "Automation Anxiety and Translators." Translation Studies, November, 1-21. https://doi.org/10.1080/14781700.2018.1543613.

Weaver, Warren. 1949. "Translation. Rockefeller Foundation Memorandum." http://www.mt-archive.info/50/Weaver-1949.pdf.

Werff, Lisa van der, Colette Real, and Theodore Lynn. 2018. "Individual Trust and the Internet." In The Routledge Companion to Trust, edited by Rosalind Searle, AnnMarie Ingrid Nienaber, and Sim B. Sitkin, 391-407. Routledge Companions in Business, Management and Accounting. Abingdon: Routledge.

Yan Ren, Xiao. 2015. "An Interview of Cloud Translation Platform." International Journal of Modeling and Optimization 5 (5): 332-36. https://doi.org/10.7763/IJMO.2015.V5.484.

\section{H.FURTHER READING (3-5 ITEMS WITH A BRIEF ANNOTATION TO EXPLAIN}

\section{WHY RECOMMENDED)}


Although none of these contributions is specifically about ethics in the translation industry, each touch on issues raised in this chapter. Abdallah is key in identifying production networks as the prevailing working environment in the contemporary translation industry in her chapter focusing on translators' agency.

Abdallah, Kristiina. 2010. “Translator's Agency in Production Networks." In Translator's Agency, edited by Tuija Kinnunen and Kaisa Koskinen, 11-46. Tampere: Tampere University Press.

Drugan identifies a lack of ongoing support for individual translators and interpreters in the course of their work.

Drugan, Joanna. 2017. "Ethics and Social Responsibility in Practice: Interpreters and Translators Engaging With and Beyond the Professions.” The Translator 23 (2): 12642. https://doi.org/10.1080/13556509.2017.1281204.

Pym engages in a discussion of ethics from the perspective of the individual translator.

Pym, Anthony. 2012. On Translator Ethics: Principles for Mediation Between Cultures. Benjamins Translation Library, v. 104. Amsterdam ; Philadelphia: John Benjamins.

\footnotetext{
${ }^{\mathrm{i}}$ For a discussion of these topics, please see Moorkens and Lewis (2019a).
} 